\title{
ABOUT PROPERTY IDENTITY
}

\section{Arnold Cusmariu}

W. V. Quine has objected that properties are philosophicaliy suspect on grounds that their identity conditions are obscure. 1 I consider this and related matters below.

\section{I}

It is a generally accepted doctrine that leibniz's Law

\section{(LL) $(x)(y)(x=y+(F)(F x \equiv F y))$}

provides logically necessary conditions for the concept of identity. But for some reason, philosophers sometimes either overlook the intended breadth of LL or else do not take it seriously enough. For some philosophers, who happened to be interested at some particular time only in a certain class of objects, 2 have felt compelled to formulate special conditions of identity for the entity of their choice, as if this was something they had to do over and above adherence to LL.

Now, I have no objection against this extra work these philosophers want to do, as long as it is realized that it is just that: extra work. They aren't in the least required to do it to settle the identity issue for their entities. LL will do that. And this applies to any entity whatever philosophers may wish to study.

of course, it applies to properties too. Property Realists need do no extra work to deal with property identity either. ${ }^{3}$ Suitably construed LL will suffice. And once this is realized, identity conditions for properties become no more obscure than identity conditions for anything else. Property Realigts can sinply use the Realist counterpart of LL,
(PI) (F)(G)(F=G $\rightarrow$ (II)(F exemplifies $11 \equiv$ G exempli- fies II) )"

to settle the identity issue for properties. 
Indeed, by comparison with PI, the usual approach t:o property identity 5

$\left(P I I^{\prime}\right)\left(F^{\prime}\right)(G)(F=G+(a)(b)((a$ expresses $F \& b$ expresses G) + a is synonymous with

b))

(where the innermost quantifiers range over open sentences), seems utterly misguided methodologically. There is little room for semantic considerations in a inat ter as exclusively ontological as identity. After all, when we ask whether the Evening Star and the Morning Star are identical we are not inclined to think the question should be answered semantically. We answer it not by reflecting on the meaning of the expressions "the Evening Star" and "the Morning Star," or on the semantic relations which might hold between them, but by considering the Evening Star and the Morning Star, $\underline{i} \cdot \underline{e}$. , the objects themselves.

Similarly here. When we ask about identity conditions for properties we want the answer to bear on properties themselves not the holding of some semantic relation between open sentences which express them. That would be changing the subject. So then we must consider the objects themselves; provided we are prepared to put language and semantics aside and take properties qua objects seriously in the first place, as Plato did. IIt is not surprising that Quine and Carnap, neither of whom ever took properties conceived as extra-linquistic objects seriously, are mainly responsible for the prominence of a semantic criterion for property identity.)

Why should philosophers find property identity problenatic in the first place? Possibly as a result of the following process: (i) they replace the wholly ontological question "When are properties the same?" with the mainly semantic question "When do two open sentences express the same property?," which (2) they in turn replace with the wholly semantic question "When do two open sentences have the same meaning?" (Problems about proposition identity get started the same way.) So the search for a semantic criterion begins and ends quickly in obscurity when doubts about synonymy are raised.

But there is no reason why we must think of properties as meanings. Plato didn't. Indeed, if doubts about synonymy are justified, we shouldn't so think of 
properties. That is not to say that meaning is not relevant to properties. It is, but only in that meaningful open sentences only can be said to express properties-a connection which hardly inplies that properties must be meanings, and hence some sort of linguistic object.

True, even though properties need not be meanings, they are still "intensions." Nothing more mysterious need be intended by this tag, however, than that properties can be exemplified by all and only the same objects, i.e., have the same extension, without being the same, as is the case with being an equilateral triangle and being an equiangular triangle. Ilow this can be so may beseen by recalling that properties are both exemplifiers and exemplifiees. We do not automatically specify all the properties a property can exemplify when we specify what exemplifies it.6

\section{I}

I want now to consider four possible objections to what I have been saying.

(i) "PI above is circular. To apply it we must already know what property is."

Granted. PI by itself will not do as an account of what a property is. But it is not intended to. Such an account ought to be forthcoming from a full-blown theory of properties, not from a criterion of identity. It is not the business of a criterion of identity to specify the entity. As I have already attended to this matter elsewhere, 7 independently of PI, the circularity objection will not work against me.8

(ii) "Philosophers do need to do extra work to settle the ratter of identity for their entities because it is difficult to formulate general logically sufficient conditions for identity, in light of Wittgenstein's objection 9 to Russell's definition of identity in Principia Mathernatica

$13.01 \quad x=y=:(\emptyset): \emptyset ! x . \supset . \emptyset ! y \quad D F$

later bolstered by Max Black's hypothesislo of a possible world of two indiscernibles."

This is a more serious, but still answerable, objection. I don't think property Realists need worry that the converse of PI

(PI') (F)(G)((H)(F exemplifies H $I$ G exemplifies II) * $F=G$ ) 
might turn out false. Wittgenstein's objection and Black's hypothesis have no force at all against properties. The possible world of two objects having all and only the same properties Black asks us to imagine is in fact incoherent if it is a world of any kind of nonindividual. ror if this world contained non-individuals, it might contain, for example, two sets having all and only the same members (since two sets having all and only the same properties would also have all and only the same members). But surely this cannot be.

But it seems to me that Black's world is incoherent even as a world of individuals. Russell was right to define identity as he did, for the following reason. A definition of identity must tell us not only when and only when we have one thing, but also when and only when we have two. That is, on the flip side of a definition of identity there must be one of diversity.

Now, in so far as $I$ understand what diversity is at all, it seeins to me that if $a$ is other than $b$, then there is a property one of them has which the other does not have (never mind how we could know this). That is what is meant by saying that we have two things and not one. But then

\section{$\left(1, L^{*}\right)(x)(y)((F)(F x \equiv F y)+x=y)$}

has to hold to give us the concept of diversity by transposition. In requiring that we give up the necessity of LL", Black's hypothesis simply robs us of our meaning postulate for diversity. What we are to put in its place or how we are to understand diversity without Ll." I cannot inagine. Black certainly does not tell us. 11

(iii) "Philosophers must still do extra work to settle the issue of identity for their entity, not because it is difficult to formulate adequate logically sufficient conditions for identity, but because such conditions must also be helpful. That is, they must tell us also how we are to determine in some particular case whether we have one thing or two. But Lik and PI * do not do this."

In the present context the objection is irrelevant, as it raises not an ontological question but an epistemological one. Unlike the previous objection, the present one does not question the truth of $L L^{*}$ or related principles. It merely insists that all such principles be able to answer also the question "llow do you know that here you have one thing and not two?" While this question is interesting and inportant, it is not one which the Realist must answer to deal with the ontological aspects 
of identity. It is, in general, bad method to attach an epistemological rider to a metaphysical question.12

In any case, $I$ don't see why $L L^{*}$ and $P I *$ are not "helpful." According to these principles, if there is a property which $\mathrm{a} / \mathrm{F}$ has and which $\underline{b} / \underline{G}$ does not have, we have two things/properties. If there is no such property, we have one. This alone will not tell us what properties in particular wolld be needed or how we are to look for thein, but presumably that should be the result of some honest toil and not merely a matter of direct inference from such general principles as LL* and PI*. (The extra work whose analytic value I questioned earlier might cone in handy here.)

(iv) "The principle LL" that indiscemibles are identical implies that an individual is nothing but a bundle of properties.13 But this view is absurd because it implies that individuals must be abstract. I" Therefore, $L^{k}$ is absurd."

I agree it is absurd to think of individuals as mere bundles of properties. But I disagree that $L L^{\text {, }}$ implies this view. For, while on the present view LL* is not compatible with there being no properties, it is perfectly compatible with there being no sets (collections, bundles, etc.), of properties or anything else. Together with $1 . L, L, L^{*}$ merely sets forth the meaning of identity, so that any proposition involving this concept can be paraphrased wholly in terins of property coexemplification. Such a paraphrase neither dispenses with individuals, in favor of some other entity, nor identifies then with some other entity. It takes no stand at all on the nature of individuals. Except for identity, it leaves everything else the same.

I have argued that there is nothing especially obscure about property identity. Whatever be the truth about identity--and here I have argued, with Russejl, that Leibniz's Law and its converse jointly exhaust that truth--it holds equally for individuals and non-individuals. The sole remaining mystery, if we can call it that, is epistemological. But that is a separate issue, which I may legitimately postpone for another occasion. 15

Salve Regina College 


\section{NOTES}

lQuine discusses the issue in several places. See "Speaking of Objects," in Ontological Relativity and Other Essays (Columbia Univ. Press, 1969), pp. 1- 25 ; The Roots of Reference (Open Court, 1974), sec. 27 and 35 ; and Word and Object (M.I.T. Press, 1960), secs.43, "l" alsd 50 .

2See for example D. Davidson, "Ihe Individuation of Events," in N. Rescher (ed.) Essays in Honor of Carl G. Heinpel (Dordrecht, 1969), pp. 216-34.

${ }^{3}$ So an enterprise such as P. Achinstein's "The Identity of Properties," American Philosophical Quarterly, II, (1971"), pP. 257-75 is needless iy elaborate. See also 11. Putnam "On Properties," in Rescher, op. cit., pp. $235-511$.

"I an using the tern "exemplifies" in much the same way that others use such terms as "instantiates," "is a case of," "is in the extension of, "satisfies" and the like, to record the "having" relation between a universal and a thing (or another universal). These terms, of course, go back to Plato, who uses "participates," "shares in" and "partakes of "when speaking of Forms and their instances.

This term is very important indeed. I will use it in the principle PI without definition, mainly because no Realist can actually define "exemplification" noncircularly. For any definition involves predication and thus must eventually resort to the concept of exemplification as prescribed by the Realist's predication paradigns, (I) a is $\Gamma$ if and only if a exemplifies $F$-ness, or (II) a bears $R$ to $\underline{b}$ if and only if the orderéd pair $(a, b)$ exemplifies $\underline{R}-\bar{n} e s s$. There is more on this and rêlated issues in my paper "Ryle's Paradox and the Concept of Exemplification," forthcoming in Vol. VII, no. 2 of Journal of Critical Analysis.

5 "Expressing" here is a triadic relation between an open sentence, a property and the language to which the open sentence belongs. The relation is intended to have existential import, in the sense that if an open sentence expresses a property then the property expressed exists. The relation is also syrtactical, in that open sentences are taken to express properties, as opposed to 
expressing relations, by virtue of the free varibales they contain. Finaliy, the expressing relation is at best contingent since what property in particular an open sentence expresses is largely a conventional matter. Thus, while " $x$ is red" expresses, in English, the property being red it could very well have expressed another.

${ }^{6}$ The same point applies to propositions. He do not automatically specify all the properties a proposition exemplifies when we specify its truth-functional properties. Thus there is no problem about logically equivalent propositions not being the same.

${ }^{7}$ See Ch. VIII of my dissertation "A Platonist I'heory of Properties," Brown University, 1977.

${ }^{8}$ See in this connection N. L. Wilson, "Facts, Events and Identity Conditions," Philosophical Studies 25 (1974), pp. 303-21, esp. pp. 303-4. Possibly the circularity objection is more successful against Davidson, for his principle of event identity is also made to do duty as meaning postulate for his concept of an event.

${ }^{9}$ See Tractatus 5.5302 , where Wittgenstein remarks: Russell's definition of ' $=$ ? is inadequate, because according to it we cannot say that two objects have all their properties in common. (Even if this proposition is never correct, it still has sense). (Pears \& McGuinness translation, Wittgenstein's italics). The point here, I take it, is that the proposition that there are two objects having all and only the same properties is meaningful, hence could be actualized, in which eventuality we would have a counterexample to Russell's definition. Thus the claim is that that definition does not contain logically sufficient conditions for the concept of identity.

${ }^{10}$ See his "The Identity of Indiscernibles," Mind 61 (1952), pp. 153-64. Black's paper is mostly a fleshing out of wittgenstein's earlier objection. He attempts to show that the proposition that there are two objects having all and only the sane properties could be actualized by inagining a possible world in which this is the case. His contention is that the principle of Identity of Indiscernibles (what I call "LL" below) is not necessarily true, (not that it is false).

${ }^{11}$ A robust defense along the same 1 ines may be found in B. Blanshard, Reason and Analysis (Open Court, 1962), Cli. 9, secs. 15-19. See also J. M. E. Mc'laggart, The Nature of Existence, Vol. I (Cambridge Univ. Press, $\overline{19215,} \overline{C h} . \bar{X}$, for another defense of $\mathrm{LL}^{*}$. 
12 Worse, of course, is to confuse the two. There is more on these methodological issues in S. A. Kripke's "Naining and. Necessity," in G. Harman and D. Davidson. (eds.), Semantics of Natural Language, (Dordrecht, 1972), Pp. $253-355$; and his "Identity and Necessity," in $M . K$. Munitz (edi) Identity and Individuation (New York Univ. $13{ }^{\circ}$

tional Blanshard eventually comes to accept this conditional. See op cit., pp. 398-99. A. J. Ayer accepts view that their justification is the sas only the weaker Identity of Indiustification is the same. See "The Papers, (Macmillan, 1954)," in his Philosophical The point is Kripke's. See "Naming and Necessity," pp. $272-73$. of course, this is not the only objection to the bundle view, merely the simplest. For a more extended discussion of the issues here see $G$. and the articles in the of Wisconsin Press, 1967); Particulars, M. J. Loux ed., (Doubleday, Universals and ${ }^{15}$ I an indebted to the editors and to Philip Quinn and Josiall Strandberg for helpful comments. 